\title{
Some aspects of use of organic containing waste for electrical and thermal energy generation
}

\author{
I A Vladimirov ${ }^{1, *}$, Liliya Mukhametova ${ }^{2}$, and $M V$ Yamashkin $^{1}$ \\ ${ }^{1}$ Peter the Great Saint-Petersburg Polytechnic University \\ ${ }^{2}$ Kazan State Power Engineering University, Kazan, Russia
}

\begin{abstract}
This article is devoted to the problem of energy generation from the non-processed part of waste, both industrial and municipal. Some aspects of use of gasification products of organic-containing wastes and landfill gas are considered. The presented comparison shows that landfill and generator gases can be attributed to the group of medium-calorific gases used both as boiler fuel and for production of liquid synthetic fuels. It should also be noted that generator and landfill gases contain a significant proportion of inert gases (from $22 \%$ to $60 \%$ ), which is significantly higher than that of natural gases. Inert gases in landfill and generator gases are different. In the first case it is $\mathrm{CO}_{2}$, in the second it is $\mathrm{N}_{2}$. Unlike solid fuel boilers, in a boiler designed to burn gaseous fuels (natural gas), synthetic gases can also be burned without significant additional reconstruction. Due to the difference in gas calorific value, the ratio of fuel to air (with a constant coefficient of excess air $\alpha$ ) will change to obtain the necessary thermal power, however, the volume of flue gases will differ slightly. Therefore, the flow sections of the boiler furnace can be saved.
\end{abstract}

\section{Introduction}

Municipal solid waste (MSW) and industrial waste management is currently a global problem. Waste must be sorted. Some of its components, such as metal, plastic, ceramics, are recyclable and reusable [1], food waste can be biodegradable. A significant part of waste (about $30 \%$ by volume of MSW) is not recyclable, the organic-containing part of such waste can be subjected to thermal utilization in order to generate thermal and electric energy [2-5]. The leaders in the field of MSW processing are Japan, where $75 \%$ of MSW are processed, USA (46\%), Switzerland (53\%) [6], Denmark (46.3\%), the Netherlands (51.7\%), Germany (66.1\%), Sweden (48 $\%)$, France (39.5\%) [7].

As a rule, organic-containing waste is a solid loose mass of various fractional compositions. The main types of organ-containing waste considered in this article include: municipal solid waste, logging debris, wood processing waste, agricultural waste: straw and biomass of cultivated plants. Therefore, during direct combustion, a solid fuel boiler is required. The efficient use of such a boiler is accentuated by the fact that solid fuel boilers are designed and calculated for a specific type of fuel with the known thermophysical properties [8]. However, the thermophysical properties of organic-containing waste are unstable, so the efficiency of such a boiler will significantly change. In some cases it cannot be used, for example, for slag with low melting temperature and upon slagging of the screen surfaces. At the same time, gas boilers do not have such a drawback [9]. To use organic-containing waste in the energy recovery cycle, it is necessary to use gaseous products obtained from waste by gasification, pyrolysis, or by collecting landfill gas. Consider some aspects of gasification of organiccontaining waste and combustion of generator gas.

\section{Materials and methods}

To determine the higher $Q_{\mathrm{h}}$ and lower $Q_{l}^{w}$ calorific values of fuel the formulas of D.I. Mendeleev are used:

$$
\begin{aligned}
& Q_{l(h)}=0.01 \cdot\left(Q_{l(h) H_{2}} \cdot H_{2}+Q_{l(h) C O} \cdot C O+\right. \\
& \left.+Q_{l(h) H_{2} S} \cdot H_{2} S+\sum Q_{l(h) C_{n} H_{m}} \cdot C_{n} H_{m}\right)
\end{aligned}
$$

where $Q_{l(h)}$ is the lower (higher) heat of combustion of generator gas components, $\left(\mathrm{MJ} / \mathrm{m}^{3}\right) ; \mathrm{H}_{2}, \mathrm{CO}, \mathrm{H}_{2} \mathrm{~S}$, $C_{n} H_{m}$ is the content of generator gas components, $\%$. When substituting the known calorific values of gases, the formula is reduced to:

- for higher calorific value of gas:

$$
\begin{aligned}
& Q_{h}=126.4 \cdot \mathrm{CO}+127.8 \cdot \mathrm{H}_{2}+ \\
& +397.8 \cdot \mathrm{CH}_{4}+630.6 \cdot \mathrm{C}_{2} H_{4}+ \\
& +699.7 \cdot \mathrm{C}_{2} \mathrm{H}_{6}+972.2 \cdot \mathrm{C}_{3} H_{8}+1285.9 \cdot \mathrm{C}_{4} H_{10}
\end{aligned}
$$

- for lower calorific value of gas:

$$
\begin{aligned}
& Q_{l}^{w}=126.4 \cdot C O+107.8 \cdot H_{2}+ \\
& +358.6 \cdot C_{4}++591.2 \cdot C_{2} H_{4}+ \\
& +638.1 \cdot C_{2} H_{6}+913.4 \cdot C_{3} H_{8}+1187.6 \cdot C_{4} H_{10}
\end{aligned}
$$

\footnotetext{
* Corresponding author: vladimirov@ nil-teplo.ru
} 
Table 1. Comparison of thermophysical characteristics of fuel gases.

\begin{tabular}{|c|c|c|c|c|c|c|c|c|c|}
\hline \multirow{3}{*}{ Gas } & \multicolumn{7}{|c|}{ Gas content, volumetric, $\%$} & \multirow{3}{*}{$\underset{\mathrm{kg} / \mathrm{m}^{3}}{\rho,}$} & \multirow{3}{*}{$\begin{array}{c}Q_{l}^{w}, \\
\mathbf{M J} / \mathbf{m}^{3}\end{array}$} \\
\hline & \multicolumn{4}{|c|}{ Combustion } & \multicolumn{2}{|c|}{ Inert gases } & \multirow[t]{2}{*}{$\mathbf{O}_{2}$} & & \\
\hline & $\mathbf{H}_{2}$ & $\mathrm{CO}$ & $\mathrm{CH}_{4}$ & $\mathrm{C}_{\mathrm{n}} \mathrm{H}_{\mathrm{m}}$ & $\mathrm{CO}_{2}$ & $\mathbf{N}_{2}$ & & & \\
\hline Biomethane [10] & & & 95 & 3 & & 1.5 & & & 36 \\
\hline $\begin{array}{l}\text { Landfill gas: [11] } \\
\text { high calorific } \\
\text { low calorific }\end{array}$ & & & $\begin{array}{l}70 \\
33\end{array}$ & - & $\begin{array}{l}30 \\
60\end{array}$ & - & - & $\begin{array}{l}1.098 \\
1.48\end{array}$ & $\begin{array}{l}25.102 \\
11.834\end{array}$ \\
\hline Semi-coke [12] & 23.5 & 6.5 & 51.5 & 4.5 & 7.0 & 5.5 & 1.5 & 0.764 & 24.65 \\
\hline Coke [12] & 57 & 6.0 & 24.0 & 3.0 & 3.0 & 7.0 & - & 0.324 & 17.6 \\
\hline Shale [12] & 24.7 & 10.0 & 16.2 & 5.0 & 16.4 & 26.8 & 0.7 & 1.040 & 13.85 \\
\hline Generator gas* & 18.1 & 24.4 & 1.6 & - & 10.3 & 45.4 & 0.2 & 1.09 & 4.5 \\
\hline Generator gas $* *$ & 13.0 & 27.6 & 0.6 & - & 6.0 & 53.2 & 0.2 & 1.141 & 5.15 \\
\hline Generator gas $* * *$ & 37.6 & 39.2 & - & - & 3.02 & 19.9 & - & 0.52 & 8.25 \\
\hline Blast-furnace [12] & 3.0 & 30 & - & - & 9.0 & 58.0 & - & 1.283 & 4.10 \\
\hline Natural [12] (Korobovskiy) & - & - & 81.5 & 14.8 & - & 3.2 & 0.5 & 0.901 & 41.45 \\
\hline $\begin{array}{c}\text { Natural [12] } \\
\text { (Igrimskiy) }\end{array}$ & - & - & 95.7 & 2.8 & - & 1.3 & 0.2 & 0.741 & 36.47 \\
\hline
\end{tabular}

The theoretically required air consumption for mixture burning $\left(\mathrm{m}^{3} / \mathrm{m}\right)$ is:

$$
\begin{aligned}
& V_{0}=0.0476 \cdot\left(0.5 \cdot \mathrm{CO}+0.5 \cdot \mathrm{H}_{2}+2 \cdot \mathrm{CH}_{4}+\right. \\
& \left.+\sum\left(m+\frac{n}{4}\right) \cdot \mathrm{C}_{m} \mathrm{H}_{n}+1.5 \cdot \mathrm{H}_{2} \mathrm{~S}-\mathrm{O}_{2}\right)
\end{aligned}
$$

When changing the compositions of gas and blast, the theoretical flow rate of blast for the complete combustion of $1 \mathrm{~m}^{3}$ of gas is calculated by the formula:

$$
V=\frac{100}{K} \cdot V_{0, O_{2}}
$$

where $\mathrm{K}$ is the oxygen content in blast, $\% . \mathrm{K}=21 \%$ for air blast;

$$
\begin{aligned}
& V_{0, O_{2}}=0.5 \cdot\left(\mathrm{H}_{2} \mathrm{O}+\mathrm{Co}\right)+1.5 \cdot \mathrm{H}_{2} \mathrm{~S}+ \\
& +\sum\left((n+m) \cdot \mathrm{C}_{n} \mathrm{H}_{m}-\mathrm{O}_{2}\right) \cdot 0.01
\end{aligned}
$$

The volume of combustion products, $\mathrm{m}^{3} / \mathrm{m}^{3}$ is determined by the formula:

$$
V_{\mathrm{RO}_{2}}=0.01 \cdot\left(\mathrm{CO}+\mathrm{CH}_{4}+\sum \mathrm{C}_{m} \mathrm{H}_{n}+\mathrm{H}_{2} \mathrm{~S}+\mathrm{CO}_{2}\right)
$$

Mass fraction of water in wet gas, $\%$ is:

$$
W_{g}=\frac{\rho_{\mathrm{H}_{2} \mathrm{O}} \cdot \mathrm{H}_{2} \mathrm{O}}{\rho_{\mathrm{CO}_{2}} \cdot \mathrm{CO}_{2}+\rho_{\mathrm{CH}_{4}} \cdot \mathrm{CH}_{4}+\rho_{\mathrm{H}_{2} \mathrm{O}} \cdot \mathrm{H}_{2} \mathrm{O}}
$$

And the volume of water vapour is:

$$
\begin{aligned}
& V_{\text {w.s. }}=0.01 \cdot\left(H_{2}+2 \cdot \mathrm{CH}_{4}+\sum \frac{n}{2} \cdot\left(C_{m} H_{n}+\right.\right. \\
& \left.+H_{2} S+0.124 \cdot W_{g}\right)+0.016 \cdot V_{0} \cdot \alpha_{\text {air }}
\end{aligned}
$$

The temperature of mixture combustion is

$$
T_{\text {combustion }}=\frac{Q_{l}^{w}+h_{m i x}+h_{\text {air }}}{V_{\text {mix }} \cdot C_{m i x}^{\prime}}
$$

or a detailed expression

$$
T_{\text {combustion }}=\frac{Q_{l}^{w}+h_{\text {mix }}+h_{\text {air }}}{V_{\mathrm{CO}_{2}} \cdot C_{\mathrm{CO}_{2}}^{\prime}+V_{\mathrm{N}_{2}} \cdot C_{\mathrm{N}_{2}}+V_{\mathrm{H}_{2} \mathrm{O}} \cdot C_{\mathrm{H}_{2} \mathrm{O}}^{\prime}+V_{\text {air }} C_{\text {air }}^{\prime}}
$$

where $h_{\text {mix }}$ and $h_{\text {air }}$ is the heat of mixture and air, respectively, $\mathrm{kJ} / \mathrm{kg}$, the values of which under normal conditions can be neglected.

The heat capacity of generator gas is determined based on the principle of additivity, i.e. the products of heat capacities of individual components by their mass fractions are summed up.

\section{Results and discussion}

The thermophysical properties of generator gas depend on the gasification method and blast composition. Using the listed formulas, the properties of landfill gas of various calorific values were calculated (boundary values were adopted depending on the MSW composition) and the generator gas obtained by various gasification technologies, taking into account various blast composition.

For clarity, the properties of generator and landfill gases are given in comparison with fossil natural gas of various fields, as well as other synthetic gases. The comparison results are shown in table 1 .

The comparison shows that landfill and generator gases can be attributed to the group of medium-calorific gases used both as boiler fuel and for production of liquid synthetic fuels. It should also be noted that generator and landfill gases contain a significant proportion of inert gases (from $22 \%$ to $60 \%$ ), which is significantly higher than that of natural gases. This fact explains its relatively low calorific value. It should be also noted that the composition of landfill gas is variable and depends on the morphological composition of 
Table 2. The amount of flue gases produced during combustion of fuels with various heat of combustion for $\alpha=1.2$.

\begin{tabular}{|c|c|c|}
\hline Parameter & Natural gas & Generator gas \\
\hline Heat of combustion $Q_{l}^{w}, \mathrm{MJ} / \mathrm{kg}$ & 35.3 & 4.96 \\
\hline Fuel consumption, $\mathrm{m}^{3} / \mathrm{s}$ & 0.283 & 7.2 \\
\hline Air consumption, $\mathrm{m}^{3} / \mathrm{s}$ & 7.218 & 5.155 \\
\hline Consumption of flue gases, $\mathrm{m}^{3} / \mathrm{s}$ & 7.845 & 7.800 \\
\hline
\end{tabular}

Table 3. Temperature of generator gas combustion

\begin{tabular}{|c|c|}
\hline Gas mixture composition & Tcombustion, $\mathbf{K}$ \\
\hline $\mathrm{CH}_{4}-40 \%, \mathrm{CO}_{2}-60 \%$ & 2498 \\
\hline $\mathrm{CH}_{4}-70 \%, \mathrm{CO}_{2}-30 \%$ & 2833 \\
\hline $\mathrm{CH}_{4}-33 \%, \mathrm{CO}_{2}-60 \%, \mathrm{H}_{2} \mathrm{O}-7 \%$ & 1975 \\
\hline $\mathrm{CH}_{4}-63 \%, \mathrm{CO}_{2}-30 \%, \mathrm{H}_{2} \mathrm{O}-7 \%$ & 2241 \\
\hline
\end{tabular}

municipal solid waste located at the landfill. For unsorted waste, biogas includes [11]:

- combustible component methane $\left(\mathrm{CH}_{4}\right)$ in the amount from 33 to $70 \%$,

- inert gas carbon dioxide $\left(\mathrm{CO}_{2}\right)$ in the amount from 60 to $30 \%$,

- impurities, their amount is insignificant, but hydrogen sulfide $\mathrm{H}_{2} \mathrm{~S}$ is presented in it,

- water vapor, the maximum content of which in landfill gas reaches $7 \%$.

Inert gases in landfill and generator gases are different. In the first case, it is $\mathrm{CO}_{2}$, in the second it is $\mathrm{N}_{2}$. Dilution of combustion gases with inert (ballast) gases impairs their flammability. The type of inert gas can significantly affect the flammability limits, and for $\mathrm{CO}_{2}$, this effect is much stronger than for $\mathrm{N}_{2}$. The concentration limits of methane ignition (the combustible component of biogas) in a mixture with $\mathrm{CO}_{2}$ are in the range from 6 to $30 \%$ [15]. There, for comparison, a similar dependence is given for a mixture of methane with inert gas $\left(\mathrm{N}_{2}\right)$; for such a mixture, the concentration limits are wider and amount to $6-42 \%$ [15].

At the lowest possible concentration of $\mathrm{CH}_{4}$ in biogas, ignition of biogas is problematic, as it is in a very narrow range of air concentrations. In such cases, a quite common technique that improves flammability is the addition of high-calorific gas from an external source (natural gas, propane, butane, etc.).

\subsection{Volume of flue gases}

Among the aspects of burning synthetic gases, it is important to note that, unlike solid fuel boilers, synthetic gases can also be burned in a boiler designed to burn gaseous fuels without significant additional reconstruction. Of course, due to the difference in the calorific value of gas, the ratio of fuel to air (at a constant coefficient of excess air $\alpha$ ) will change to obtain the necessary thermal power, however, the volume of flue gases will differ slightly. Therefore, the flow sections of the boiler furnace can be saved. The results of calculating the volume of flue gases during combustion of natural and generator gases at $\alpha=1.2$ are shown in table 2 .

The presented data allow us to conclude that the generator gas, as well as biogas, can be used in various combustion devices, for both industrial (steam and hot water boilers, process furnaces, drying plants, heat generators, heating devices, etc.), and domestic (heating stoves, hot water devices, etc.) purposes without significant reconstruction. Due to changes in gas and air flow rates, only burner devices should be replaced. For efficient and reliable burning of generator gas and optimization of furnace devices, it is advisable to study the propagation velocity of the combustion front, the length of flame and the completeness of combustion in burners of various types for various biogas composition and flow rates of blast air.

Thus, it is possible to convert the existing miniCHPPs to work on generator or landfill (in case of a mini-CHPP located near the MSW landfill) gas. For such a transfer, an add-on to a mini-CHP plant with a gas generator and a generator gas purification system (if necessary) will be required. The boiler room (with the exception of burners), turbine equipment, or a gas piston unit, as well as flue gas removal and purification system can be left unchanged.

\subsection{Generation of nitrogen oxides}

The formulas listed above were used to calculate the combustion temperature of generator gas as a function of gas mixture composition. The calculation results are shown in table 3 .

It should be noted that the calculation results differ from the Russian literature data [15], which show that when burning the $2 \mathrm{CH}_{4}+\mathrm{CO}_{2}$ mixture in air, the flame temperature is $2025 \mathrm{~K}$. Therefore, experimental confirmation is required to correctly determine the combustion temperature using the proposed formulas.

At the same time, when burning natural gas, the temperature in the combustion zone reaches 2200-2500 $\mathrm{K}$ [16]. The combustion temperatures for natural and generator gases are comparable, the methods for reducing the formation of nitrogen oxides during their combustion can be the same [17]. 
The presence of $\mathrm{SO}_{\mathrm{X}}$ in the combustion products is also not desirable in the thermotechnical sense, since it prevents deep utilization of heat of combustion products [18]. When combustion products are cooled below the dew point, sulfuric acid $\mathrm{H}_{2} \mathrm{SO}_{4}$ is formed from sulfur oxides, which causes intense corrosion of convective surfaces (the speed of which can reach $1 \mathrm{~mm}$ per year). Therefore, in case of energetic use of biogas, it is advisable to clean it from $\mathrm{H}_{2} \mathrm{~S}$. The presence of sulfur oxides in the combustion products can be eliminated by preliminary purification of generator and landfill gases from $\mathrm{H}_{2} \mathrm{~S}$, for example, using special absorbers (methanol, amines, activated carbon, aluminum oxide, etc.). If $\mathrm{H}_{2} \mathrm{~S}$ content in gas is high, the installations catching it can be supplemented with sections for production of elemental sulfur and sulfuric acid. However, this solution requires a separate feasibility study to calculate the minimum $\mathrm{H}_{2} \mathrm{~S}$ content in gas at which the sulfur or sulfuric acid production unit will be profitable.

\section{Conclusion}

The organic-containing waste can be used to produce electrical and thermal energy both through direct burning, and with their preliminary gasification. This is one of the most effective ways to handle non-recyclable waste.

Direct burning must be carried out using specially designed combustion devices, the design of which depends on the morphological composition and thermophysical properties of organic-containing waste.

The preliminary gasification of waste has some advantages:

1. The possibility of utilization gasification products in a binary cycle, or in gas-piston units. It enables applying the principle of cogeneration in energetic use of organic-containing waste with greater efficiency.

2. When operation of an existing boiler unit is converted from natural to generator or landfill gas, it is necessary to replace the burner devices. The flow sections of the furnace remain the same due to the almost unchanged volume of flue gases.

The simplest way to use non-recyclable waste for energy production is to perform a preliminary sorting already at the stage of their formation (that is, directly at the factory or by citizens). If waste sorting is provided by law, and all the materials that make up waste are premarked, the production of energy from waste becomes more economical by reducing the cost of sorting. The use of non-processed organic-containing waste for energy production should be considered when developing long-term plans and strategies for energy supply in the regions, as well as waste management as a priority measure.

\section{References}

[1] H. Sözer, H. Sözen, Waste capacity and its environmental impact of a residential district during its life cycle, Energy Reports 6, 286-296 (November 2020).
[2] N. Politaeva, Y. Smyatskaya, R. Al Afif, C. Pfeifer, L. Mukhametova, Development of Full-Cycle Utilization of Chlorella sorokiniana Microalgae Biomass for Environmental and Food Purposes, Energies 13, 10, 2648 (2020).

[3] A.A. Sinitsyn, N.N. Boytsova, I.G. Akhmetova, S.O. Makoev, A. Asadpoori, O.A. Stepanov, N.V. Rydalina, E.O. Antonova, B.G. Aksenov, Study of operation of power-generating devices of gaseous fuels combustion, International Journal of Mechanical Engineering and Technology 10, 2, 1480-1490 (2019).

[4] A. Fedyukhin, I. Sultanguzin, A. Gyul'Maliev, V. Sergeev, Biomass pyrolysis and gasification comprehensive modeling for effective power generation at combined cycle power plant, Eurasian Chemico-Technological Journal 19, 3, 245-253 (2017)

[5] L.E. Bell, Cooling, heating, generating power, and recovering waste heat with thermoelectric systems, Science 321, 5895, 1457-1461 (12 September 2008).

[6] H. Ruohomaa, N. Ivanova, From solid waste management towards the circular economy and digital driven symbiosis, IOP Conference Series: Earth and Environmental Science 337, 1, 012032 (18 November 2019).

[7] Eurostat database [Electrical resource]. Available at: http://ec.europa.eu/eurostat/data/database (accessed: 12.04.2020).

[8] K. Jesionek, M. Kantorek, H. Karcz, Main problems concerning co-firing biomass mixture with hard coal in pulverized-fuel boilers, 27th Annual International Pittsburgh Coal Conference 2010, PCC 2010 2, 1300-1308 (2010).

[9] A. Szkarowski, S. Janta-Lipińska, T. Dąbrowski, Research on co-combustion of gas and oil fuels, Rocznik Ochrona Srodowiska 20, 1515-15299 (2018).

[10] E.S. Pantchava, V.A. Pozharnov, L.V. Zysin, et al., Biomass energy conversion, Russian experience, Heat and Power Engineering 5, 33-38 (1996).

[11] V. Maslikov, E. Negulyaeva, A. Cheremisin, A. Chusov, D. Molodtsov, A. Stroganov, Experimental assessment of biogas and leachate emissions from MSW landfills for energy reclamation with the aim of sustainable urban development, Solid State Phenomena 871, 199-207 (2016).

[12] Industrial heat power engineering and heat engineering: reference book (Moscow: Energoatomizdat, 551, 1983).

[13] V.V. Sergeev, Gasification of plant biomass (SPb.: Publishing house of the Polytechnic, University, 242, 2016)

[14] A.N. Brattsev, V.A. Kuznetsov, V.E. Popov, A.A. Ufimcev, Arc Gasification of Biomass: Example of Wood Residue, High temperature 49, 2, 244-248 (2011).

[15] A.S. Isserlin, Foundations of burning gas fuel (Leningrad: Nedra, 356, 1987).

[16] H.K. Kayadelen, Effect of natural gas components on its flame temperature, equilibrium combustion products and thermodynamic properties, 
Journal of Natural Gas Science and Engineering 45, 456473 (2017).

[17] M.H. Waldner, R. Halter, A. Sigg, B. Brosch, H.J. Gehrmann, M. Keunecke, Energy from Waste Clean, efficient, renewable: Transitions in combustion efficiency and NOx control, Waste Management 33, 2, 317-326 (February 2013).

[18] R. Saidur, E.A. Abdelaziz, A. Demirbas, M.S. Hossain, S. Mekhilef, A review on biomass as a fuel for boilers, Renewable and Sustainable Energy Reviews 15, 5, 2262-2289 (June 2011). 